\title{
The Effect of Ketamine and Saffan on the $\beta$-Endorphin and ACTH Response to Hemorrhage in the Minipig
}

\author{
T. RUANE-O'HORA, W. J. HALL, F. MARKOS \\ Department of Physiology, University College Cork, Cork, Ireland
}

Received June 30, 2008

Accepted October 6, 2008

On-line December 17, 2008

\section{Summary}

The endocrine response is an important component of the physiological response to blood loss. There is some variability in reported levels of certain hormones during hemorrhage such as the stress hormone adrenocorticotrophic hormone (ACTH). Therefore, the effect of two anesthetic agents, ketamine and saffan, on ACTH and $\beta$-endorphin levels during hemorrhage was assessed in 12 minipigs. The animals were divided into two groups, group I saffan and group II ketamine $(n=6)$. Pigs were subjected to a continuous fixed volume hemorrhage under one of the above anesthetics while spontaneously breathing. Blood pressure and heart rate responses were recorded together with $\beta$-endorphin and ACTH levels both before and at 10, 20, 30, 40 min after the onset of bleeding. ACTH levels were higher in the ketamine-anesthetized pigs and rose significantly faster with falling blood pressure than ACTH measured in pigs under saffan anesthesia. In contrast, the hemorrhage induced $\beta$-endorphin increase was not significantly different between the two anesthetic groups. These results indicate that choice of anesthetic agent is important when investigating the hormone response to hemorrhage and may account for the variable hormone levels in the published literature to date.

\section{Key words}

Anesthesia $\bullet \beta$-endorphin $\bullet$ ACTH

\section{Corresponding author}

T. Ruane-O'Hora, Department of Physiology, University College Cork, Cork, Ireland. Fax: +353-0214205370. E-mail: t.ruaneohora@ucc.ie

\section{Introduction}

In vivo animal models are essential in investigating the physiological response to blood loss (Bertolini et al. 1986, Yilmazlar et al. 2000, Kurita et al. 2007, Rivera-Chavez et al. 2007). Hemorrhage results in a variety of well-known hemodynamic changes, such as increased cardiac output and heart rate, together with the less recognized but potentially important hormonal alterations (Schadt and Ludbrook 1991). For example, increasing levels of $\beta$-endorphin, an opioid, have been shown during hemorrhage and this provided evidence that opioids may contribute to the pathophysiology of hemorrhagic shock (Lang et al. 1982, Chernow et al. 1986, Gurll et al. 1986, Tuggle and Horton 1986, O'Benar et al. 1987). Furthermore, naloxone, an opioid receptor antagonist, has been shown to have an anti-shock effect following circulatory shock (Holaday and Faden 1978). Similarly, the levels of adrenocorticotrophic hormone (ACTH) are also increased during hemorrhage (Bereiter et al. 1984, 1986, Darlington et al. 1986, O'Benar et al. 1987). Both hormones form two limbs of an important physiolological opioid/anti-opioid system in the body, with ACTH being the anti-opioid, and it is suggested that this is disrupted by hemorrhage and hence contributes to the pathophysiology of shock (Bertolini 1995). In fact it has been shown that injection of ACTH aided resuscitation from hemorrhage in anaesthetized rats (Bertolini 1995), and clinically in humans (Noera et al. 2001). As well as its anti-opioid effects, the treatment with ACTH has also suppressed the inflammatory response after hemorrhage, together with activation of an anti-inflammatory reflex (Giuliani et al. 2007, Guarini et al. 2003, 2004), further contributing to its potential 
therapeutic value.

However, the physiological $\beta$-endorphin and ACTH response is also variable, depending on the anesthetic used, e.g. ketamine is an inhibitor of ACTH release in sheep (Powers and Wood 2007), whereas halothane stimulates ACTH release more than isoflurane in rabbits (Gil et al. 2007). Finally, $\beta$-endorphin levels have been shown to increase in pigs under ketamine anesthesia (Gerard et al. 1996). It is possible that the variation in response to hemorrhage may be due to the choice of anesthetic, since it is well known that the response of these two hormones during hemorrhage differs in the anaesthetized versus the conscious state (Schadt and Ludbrook 1991). We examined the effect of general anesthesia on the $\beta$-endorphin and ACTH response to hemorrhage in pigs under saffan and ketamine anesthesia. Both of these anesthetics are commonly used in experimental animals.

\section{Methods}

\section{Ethical Approval}

This study was carried out under license issued by the Department of Health, Ireland as directed by the Cruelty to Animals Act Ireland and EU Statutory Instructions and local University ethics committee.

Twelve Vietnamese Yucatan hybrid pigs (19-24 kg) bred and housed at the Biological Services Unit of University College Cork were used for these experiments. Animals were fed on a standard pig diet and allowed water ad libitum and were fasted for $24 \mathrm{~h}$ before experiments. Pigs were pre-medicated with ketamine hydrochloride $(10 \mathrm{mg} / \mathrm{kg}$ i.m.), and later assigned to two groups based on the anesthetic to be used during bleeding. In both groups an intravenous catheter was inserted in the marginal ear vein.

\section{Group I ( $n=6)$}

General anesthesia was induced with $2 \mathrm{mg} / \mathrm{kg}$ saffan (Pitman-Moore) $(12 \mathrm{mg} / \mathrm{ml}, 9 \mathrm{mg}$ alphaxalone and $3 \mathrm{mg}$ alphadolone acetate) administered via the ear vein, and maintained by continuous infusion at a rate of 12 $\mathrm{mg} / \mathrm{kg} / \mathrm{h}$, using a microprocessor-controlled syringe pump (Harvard, Pump 22).

\section{Group II (n=6)}

As ketamine is a dissociative anesthetic it was decided to carry out the surgery using halothane 2-3\% (Fluothane, Zeneca Ltd, UK) for induction, with nitrous oxide and oxygen, and 1-2 \% for maintenance. On completion of surgery, gaseous anaesthesia was discontinued and a continuous infusion of ketamine (Ketalar, Park Davis UK, $50 \mathrm{mg} / \mathrm{ml}$ ) was commenced via the ear vein at a rate of $20 \mathrm{mg} / \mathrm{kg} / \mathrm{h}$ using a microprocessor-controlled syringe pump (Harvard, Pump 22).

Depth of anesthesia was assessed regularly by checking for response to a painful stimulus. Bilateral femoral artery cannulations were carried out in both groups, for subsequent blood pressure monitoring, blood sampling and bleeding. Blood pressure was monitored using a pressure transducer (Statham P23 AA) and an ECG was also recorded. Both the transducer and the leads were connected to a computerized amplifier unit (MacLab, ADInstruments, UK) allowing digitized recording of all data, which in turn was fed to a computer (Apple Mac, Power PC) where the data were recorded using ADInstruments software, UK. Following instrumentation, animals were heparinized with 250 units $/ \mathrm{kg}$ of heparin (Leo Laboratories) and transferred to a specially made hammock, which allowed the animal to be supported in a comfortable yet restrained horizontal position. At this stage animals were kept under observation, but left undisturbed for two hours, before commencement of bleeding. This 2-h waiting period was partly to ensure that levels of halothane and nitrous oxide in the circulation of Group II animals would be minimal, and unlikely to interfere with the study in this group, where ketamine was the anesthetic of interest. In a previous study using halothane in swine an end tidal concentration of just $0.12 \%$ was recorded just $45 \mathrm{~min}$ after discontinuing the drug, which was administered in a dose range of 0.6-1.63\% (Brower and Merin 1979).

After the 2-h control period bleeding was commenced from a femoral arterial line using to a roller pump (Watson Marlow, Smith \& Nephew) at a fixed rate of $1 \mathrm{ml} / \mathrm{min} / \mathrm{kg}$ body weight, until death occurred. Blood was collected into a graduated cylinder to measure volume lost. Control blood samples $(10 \mathrm{ml})$ for measurement of $\mathrm{ACTH}$ and $\beta$-endorphin were taken $30 \mathrm{~min}$ before and at the start of bleeding (time zero). Once bleeding commenced, blood was sampled at $10 \mathrm{~min}$ intervals. In all cases blood was replaced with an equal volume of saline. Samples were taken into plastic EDTA tubes and $1 \mathrm{ml}$ of the protease inhibitor aprotinin (Sigma) was added. The tubes were immediately placed on ice, and later centrifuged (Sorvall, RT6000) for $15 \mathrm{~min}$. Immediately afterwards plasma was drawn off into plain 
plastic tubes and frozen at $-40{ }^{\circ} \mathrm{C}$, for subsequent assay of ACTH and $\beta$-endorphin.

\section{Adrenocorticotrophic hormone (ACTH) assay}

This hormone was assayed using a commercially available kit (Nichols Institute Diagnostics). Samples were assayed in duplicate, $200 \mu \mathrm{l}$ of plasma required for each sample. Assay sensitivity was $1 \mathrm{pg} / \mathrm{ml}$.

\section{$\beta$-endorphin assay}

A Nichols Institute assay kit was also used. Samples were assayed in duplicate, $200 \mu 1$ of plasma required for each sample. Assay sensitivity was $14 \mathrm{pg} / \mathrm{ml}$.

\section{Statistical analysis}

Results are expressed as means \pm S.E.M ( $\mathrm{n}=6$ for both groups). One-way analysis of variance (ANOVA) was used to compare baseline values. In Figure 2 twoway analysis of variance with repeated measures on both factors was used (two-way ANOVA) to assess the hormone response over the entire period of bleeding. This provides information on whether the entire response curve to hemorrhage differs significantly between the two anesthetic groups. This is important, since we are not interested in identifying a particular time point at which the hormone response may be different. Finally, homogeneity of the regression lines obtained in Figures 3 and 4 was compared using analysis of covariance (ANCOVA). $\mathrm{P}<0.05$ was taken as significant.

\section{Results}

Before the onset of hemorrhage commenced baseline values were as follows: for Group I saffan pigs, heart rate averaged $109 \pm 15$ beats/min (range: $70-178$ ), and mean arterial pressure was $138 \pm 6 \mathrm{~mm} \mathrm{Hg}$ (range: 114-156). Neither values were significantly different from the corresponding heart rate and mean blood pressure in the group II, ketamine pigs which were $102 \pm 9$ beats/min (range: $75-133$ ) and $145 \pm 8 \mathrm{~mm} \mathrm{Hg}$ (range: 117-170), respectively.

Control ACTH levels averaged $11.4 \pm 3.4 \mathrm{pg} / \mathrm{ml}$ (range: 6.7-27.7) in the saffan group, but this was significantly higher in the ketamine group giving a mean value of $63.3 \pm 14.4 \mathrm{pg} / \mathrm{ml}$ (range: $31-108 ; \mathrm{P}=0.006$ oneway ANOVA). In contrast, $\beta$-endorphin was $14.8 \pm 1.8 \mathrm{pg} / \mathrm{ml}$ (range: $11-22.5$ ) in group I which was not significantly different to the control levels measured in group II which averaged $12.1 \pm 0.7 \mathrm{pg} / \mathrm{ml}$ (range:

\section{6-15.1; $\mathrm{P}=0.19$ one-way ANOVA).}

Figure 1 shows that the heart rate (Fig. 1A) and blood pressure (Fig. 1B) response to hemorrhage was not significantly different between the two anesthetic groups ( $\mathrm{P}=0.97$ for heart rate and $\mathrm{P}=0.47$ for blood pressure, two-way ANOVA).
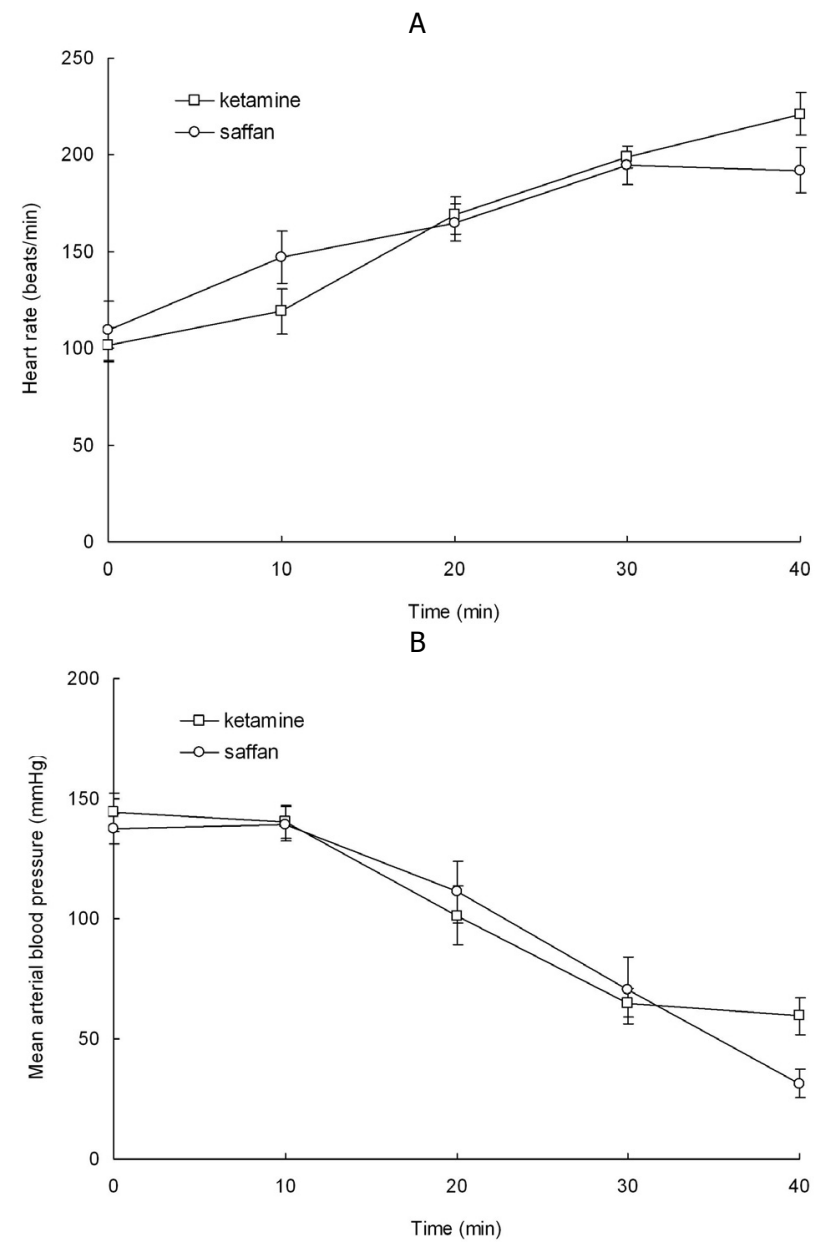

Fig. 1. Heart rate (A) and blood pressure (B) changes during progressive blood loss. Values shown are before (time 0 ) and at 10 min intervals during hemorrhage with ketamine or saffan anesthesia. There was no significant difference in the response to hemorrhage between both anesthetics.

The effect of choice of anesthesia on the ACTH response to hemorrhage

ACTH levels increased during hemorrhage in both groups (Fig. 2A), as mentioned the control ACTH levels prior to hemorrhage were significantly higher in the ketamine group. Despite this, ACTH levels increased significantly more in the ketamine-anesthetized pigs during hemorrhage than in the saffan-anesthetized pigs (Fig. 2A, $\mathrm{P}<0.00001$ two-way ANOVA). Furthermore, the actual rate of increase in ACTH accompanying the fall in blood pressure was also significantly greater in the 
ketamine group (Fig. 3), increasing at a rate of 5.5 $\mathrm{pg} / \mathrm{ml} / \mathrm{mm} \mathrm{Hg}$ for ketamine compared to an increase of $2.2 \mathrm{pg} / \mathrm{ml} / \mathrm{mm} \mathrm{Hg}$ in the saffan group $(\mathrm{P}=0.028$, ANCOVA).

A

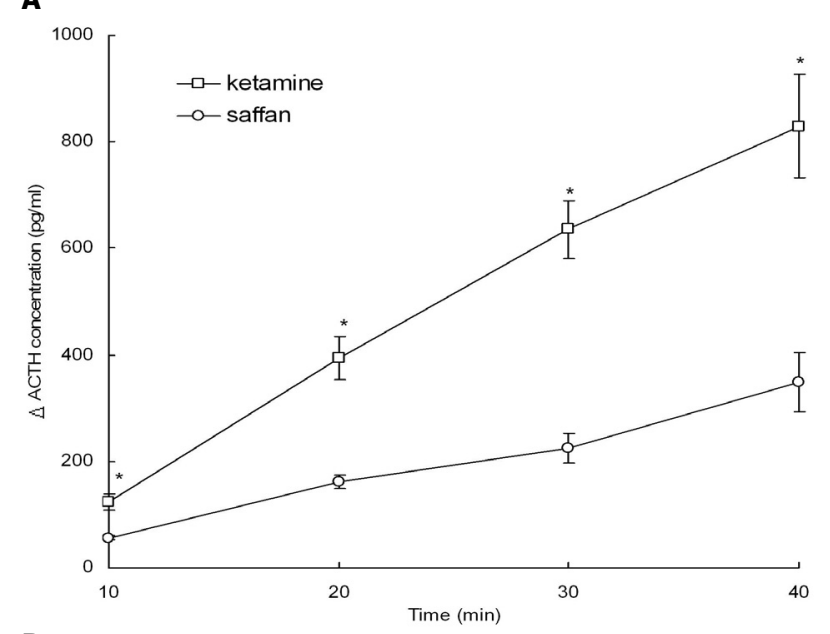

B

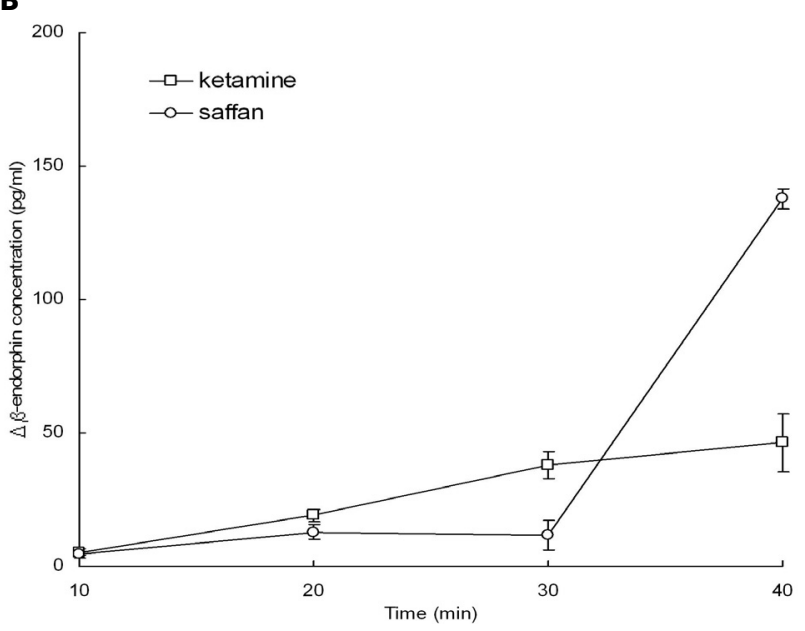

Fig. 2. The $A C T H$ and $\beta$-endorphin response to hemorrhage. ACTH levels during hemorrhage $(A), \beta$-endorphin levels during hemorrhage $(B)$. Values shown are the change from control at each time interval during hemorrhage, under ketamine and saffan anesthesia. * $\mathrm{P}<0.05$ two-way ANOVA with repeated measures on both factors.

The effect of choice of anesthesia on the $\beta$-endorphin response to hemorrhage

In contrast to ACTH, $\beta$-endorphin control levels were not significantly different between the two anesthetic groups, in addition levels of the hormone were also not significantly different over the time course of hemorrhage (Fig. 2B) $(\mathrm{P}=0.16,2$ way ANOVA). Figure $2 \mathrm{~B}$ shows that there was a large reading for $\beta$-endorphin in the saffan group at $40 \mathrm{~min}$. We decided to use two-way ANOVA with repeated measures on both factors to analyze the data, this reducing the chances that aberrant data at a single time point would affect the conclusion, since we are primarily interested in assessing the pattern of the response to hemorrhage over the entire period of blood loss, and not at a single time point. Finally, the rate of increase of $\beta$-endorphin (Fig. 4) was not significantly different between the two groups, for ketamine $\beta$-endorphin increased at a rate of $0.44 \mathrm{pg} / \mathrm{ml} / \mathrm{mm} \mathrm{Hg}$ and for the saffan group the rate was $0.98 \mathrm{pg} / \mathrm{ml} / \mathrm{mm} \mathrm{Hg}$ (Fig. 4) ( $\mathrm{P}=0.2$ ANOVA). In addition the adjusted means for the two groups in Figure 4 were also not significantly different ( $\mathrm{P}=0.34$ ANCOVA).

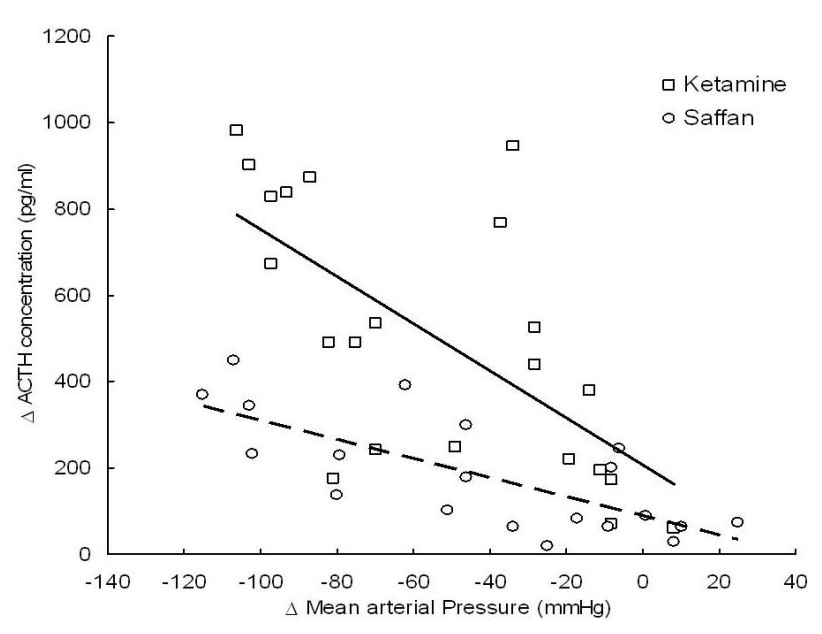

Fig. 3. Change in arterial blood pressure versus change in ACTH levels during hemorrhage under ketamine and saffan anesthesia. Solid line is for ketamine $(r=0.66)$, and broken line shows the regression for saffan $(r=0.73)$. ACTH levels increased at a faster rate in pigs under ketamine anesthesia compared to pigs under saffan anesthesia $(P<0.05$ ANCOVA).

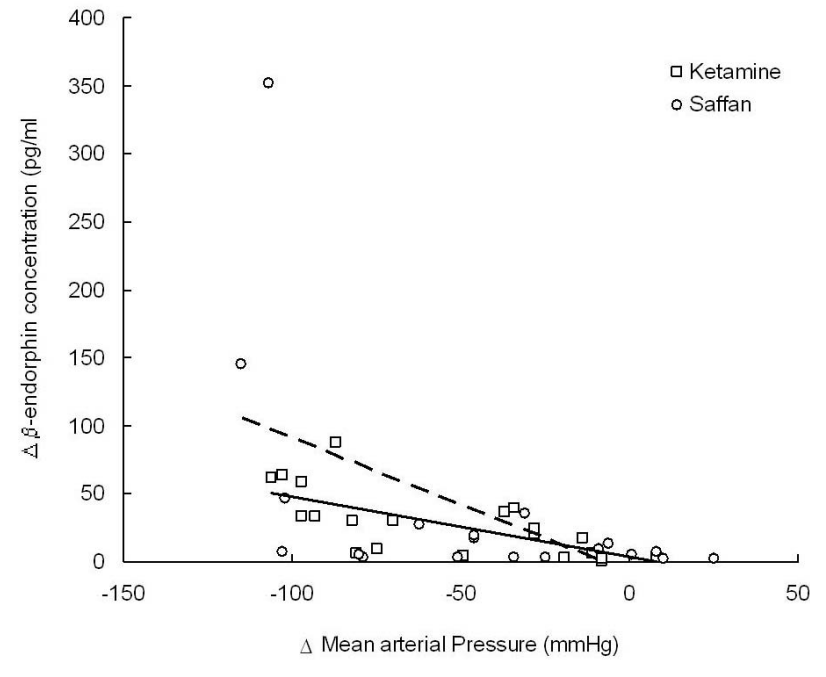

Fig. 4. Change in arterial blood pressure versus change in $\beta$-endorphin levels during hemorrhage under ketamine and saffan anesthesia. Solid line is for ketamine $(r=0.68)$ and broken line shows the regression for saffan $(r=0.52)$. There was no significant difference between the endorphin levels with both anesthetics (ANCOVA). 
The survival time (i.e. the time in minutes after hemorrhage began until mean blood pressure fell below $20 \mathrm{~mm} \mathrm{Hg}$ ) was found to be significantly different between the two groups with mean values of $49.6 \pm 1.5$ and 41.8 $\pm 1.1 \mathrm{~min}$ for ketamine and alphaxalone/ alphadolone, respectively ( $\mathrm{P}<0.05$, one-way ANOVA).

\section{Discussion}

The main finding of this study was that hemorrhage under ketamine anesthesia resulted in a greater rate of increase in ACTH with decreasing blood pressure than in pigs subjected to hemorrhage while under saffan (Fig. 3). Furthermore, the peak level recorded after $40 \mathrm{~min}$ of bleeding, with ketamine $849 \mathrm{pg} / \mathrm{ml}$ approx (though not alphaxalone/alphadolone) was well above the peak level reported in conscious pigs $518 \mathrm{pg} / \mathrm{ml}$ (O’Benar et al. 1987). The average blood loss as reported in these conscious pigs was $38.5 \mathrm{ml} / \mathrm{kg}$, whereas the average loss in our experiments was in fact less at $34-35 \mathrm{ml} / \mathrm{kg}$.

However, the increase in $\beta$-endorphin levels during hemorrhage did not differ between the two anesthetic groups (Fig. 4). There was no significant difference in the heart rate and blood pressure response to hemorrhage with either anesthetic. Our results show that the choice of anesthetic is an important factor to be considered when investigating hormonal responses to hemorrhagic shock using animal models, because it could potentially account for the variable results previously reported. A depressant effect of anesthesia may provide a possible explanation for the lack of an effect of hemorrhage on the $\beta$-endorphin response in the present study, since higher levels have been shown in conscious pigs during hemorrhage (O’Benar et al. 1987). However, higher levels of $\beta$-endorphin have been reported in an other study on hemorrhage carried out under anesthesia (Tuggle et al. 1986) compared to the study of O'Benar et al. (1987).
We did not carry out a set of experiments in conscious pigs as we felt this was both unnecessary and perhaps even unethical, in view of the data of O'Benar et al. (1987) which is quite clear. There are also many similarities between their experiments and ours. Both groups used pigs, both protocols used a fixed volume rather than fixed pressure model of hemorrhage and at the end of the hemorrhage period both the conscious pigs and our animals had lost similar though not identical amounts of blood. The major difference was that their animals were conscious while ours were anesthetized.

Ketamine was chosen as one of the anesthetics in the present study because it is widely acknowledged as an appropriate anesthetic to be used in clinical cases of hemorrhagic shock (Craven 2007), and is also used as a research anesthetic (DeClue et al. 2008, Valentino et al. 2008). Although not used as an anesthetic in humans, saffan is a commonly used general anesthetic in in vivo animal research as well as veterinary medicine (Gaudy et al. 1986, McAllen and May 1994, Mackway-Jones et al. 1999, Girolani et al. 2002, DeClue et al. 2008).

In summary, our results show greater changes in the ACTH response to hemorrhage under ketamine anesthesia when compared with saffan. In the context of a physiological anti-opioid response this could be viewed as an additional endocrine benefit of ketamine, which would complement its well know cardiovascular advantages (Craven 2007) in certain clinical situations, e.g. emergency surgery in patients where blood loss has or is likely to occur. However, more robust clinical studies would be required to assess this possible antiopioid benefit.

\section{Conflict of Interest}

There is no conflict of interest.

\section{Acknowledgements}

We gratefully acknowledge the technical assistance of Mr. Kieran McDonnell and Mr. Stephen Dineen.

\section{References}

BEREITER DA, ZAID AM, GANN DS: Adrenocorticotropin response to graded blood loss in the cat. Am J Physiol 247: E398-E404, 1984.

BEREITER DA, ZAID AM, GANN DS: Effect of rate of hemorrhage on release of ACTH in cats. Am J Physiol 250: E76-E81, 1986.

BERTOLINI A, GUARINI S, ROMPIANESI E, FERRARI W: Alpha-MSH and other ACTH fragments improve cardiovascular function and survival in experimental hemorrhage shock. Eur J Pharmacol 130: 19-26, 1986. 
BERTOLINI A: The opioid/anti-opioid balance in shock: a new target for therapy in resuscitation. Resuscitation 30: 29-42, 1995.

BROWER RW, MERIN RG: Left ventricular function and compliance in swine during halothane anesthesia. Anesthesiology 50: 409-415, 1979.

CHERNOW B, RAYMOND LAKE C, TEICH S, MOUGEY EH, MEYERHOFF J, CASEY LC, RAYMOND FLETCHER J: Hemorrhagic hypotension increases plasma beta-endorphin concentrations in the nonhuman primate. Crit Care Med 14: 505-507, 1986.

CRAVEN R: Ketamine. Anaesthesia 62 (Suppl 1): 48-53, 2007.

DARLINGTON DN, SHINSAKO J, DALLMAN MF: Medullary lesions eliminate ACTH responses to hypotensive hemorrhage. Am J Physiol 251: R106- R115, 1986.

DeCLUE AE, COHN LA, LECHNER ES, BRYAN ME, DODAM JR: Effects of subanesthetic doses of ketamine on hemodynamic and immunologic variables in dogs with experimentally induced endotoxemia. Am J Vet Res 69: 228-232, 2008.

GAUDY JH, BERGERET S, BOITIER J, FERRACCI F: Ventilatory effects of oxygen-enriched mixtures in the dog under althesin anaesthesia. Br J Anesth 58: 99-102, 1986.

GERARD H, SENSKY PL, BROOM DM, PERREMANS S, GEERS R: Influences of type of anaesthesia on cortisol, beta-endorphin and heart rate in pigs. Vet Res 27: 219-226, 1996.

GIL AG, SILVÁN G, ILLERA JC: Pituitary-adrenocortical axis, serum serotonin and biochemical response after halothane or isoflurane anaesthesia in rabbits. Lab Anim 41: 411-419, 2007.

GIROLAMI A, LITTLE RA, FOËX BA, DARK PM: Hemodynamic responses to fluid resuscitation after blunt trauma. Crit Care Med 30: 385-392, 2002.

GIULIANI D, MIONI C, BAZZANI C, ZAFFE D, BOTTICELLI AR, CAPOLONGO S, SABBA A, GALANTUCCI M, IANNONE A, GRIECO P, NOVELINNO E, COLOMBO G, TOMASI A, CATANIA A, GUARINI S: Selective melanocortin MC4 receptor agonists reverse haemorrhagic shock and prevent multiple organ damage. Br J Pharmacol. 150: 595-603, 2007.

GUARINI S, ALTAVILLA D, CAINEZZO MM, GIULIANI D, BIGIANI A, MARINI H, SQUADRITO G, MINUTOLI L, BERTOLINI A, MARINI R, ADAMO EB, VENUTI FS, SQUADRITO F: Efferent vagal fibre stimulation blunts nuclear factor- $\mathrm{KB}$ activation and protects against hypovolemic hemorrhagic shock. Circulation 107: 1189-1194, 2003.

GUARINI S, CAINAZZO MM, GIULIANI D, MIONI C, ALTAVILLA D, MARINI H, BIGIANIA, GHIARONI V, PASSANITI M, LEONE S, BAZZANI C, CAPUTI AP, SQUADRITI F, BERTOLINI A: Adrenocorticotropin reverses hemorrhagic shock in anesthetized rats through the rapid activation of a vagal anti-inflammatory pathway. Cardiovasc Res 63: 357-365, 2004.

GURLL NJ, REYNOLDS DG, HOLADAY JW: Evidence for a role of endorphins in the cardiovascular pathophysiology of primate shock. Crit Care Med 6: 521-530, 1988.

HOLADAY JW, FADEN AI: Naloxone reversal of endotoxin hypotension suggests role of endorphins in shock. Nature 275: 450-451, 1978.

KURITA T, TAKATA K, URAOKA M, MORITA K, SANJO Y, KATOH T, SATO S: The influence of hemorrhagic shock on the minimum alveolar anesthetic concentration of isoflurane in a swine model. Anesth Analg 105: 1639-1643, 2007.

LANG RE, BRUCKNER UB, HERMANN K, KEMPF B, RASCHER W, STURM V, UNGER TH, GANTEN D: Effect of hemorrhagic shock on the concomitant release of endorphin and enkephalin-like peptides from the pituitary and adrenal gland in the dog. Adv Biochem Psychopharmacol 33: 363-368, 1982.

MACKWAY-JONES K, FOËX BA, KIRKMAN E, LITTLE RA: Modification of the cardiovascular response to hemorrhage by somatic afferent nerve stimulation with special reference to gut and skeletal muscle blood flow. J Trauma 47: 481-485, 1999.

MCALLEN RM, MAY CN: Effects of preoptic warming on subretrofacial and cutaneous vasoconstrictor neurons in anaesthetized cats. J Physiol Lond 481: 719-730, 1994.

NOERA G, LAMARRA M, GUARINI S, BERTOLINI A: Survival rate after early treatment for acute type-A aortic dissection with ACTH-(1-24). Lancet 358: 469-470, 2001. 
O'BENAR JD, HANNON JP, PETERSON JL, BOSSONE CA: Beta-endorphin, ACTH and cortisol response to hemorrhage in conscious pigs. Am J Physiol 252: R953-R958, 1987.

POWERS MJ, WOOD CE: Ketamine inhibits fetal ACTH responses to cerebral hypoperfusion. Am J Physiol 292: R1542-R1549, 2007.

RIVERA-CHAVEZ FA, HUERTA S, BROWN R, YORK GB, MINEI JP: Resuscitation from hemorrhagic shock comparing standard hemoglobin-based oxygen carrier (HBOC)-201 versus $7.5 \%$ hypertonic HBOC-201. J Trauma 63: 1113-1119, 2007.

SCHADT JC, LUDBROOK J: Hemodynamic and neurohumoral responses to acute hypovolemia in conscious mammals. Am J Physiol 260: H305-H318, 1991.

TUGGLE DW, HORTON JW: beta-Endorphin in canine hemorrhagic shock. Surg Gynecol Obstet 163: 137-144, 1986.

VALENTINO DJ, WALTER RJ, DENNIS AJ, NAGY K, LOOR MM, WINNERS J, BOKHARI F, WILEY D, MERCHANT A, JOSEPH K, ROBERTS R: Acute effects of MK63 stun device discharges in miniature swine. Mil Med 173: 167-173, 2008.

YILMAZLAR A, YILMAZLAR T, OZCAN B, KUTLAY O: Vasopressin, renin, and adrenocorticotropic hormone levels during the resuscitation of hemorrhagic shock in dogs. J Emerg Med 18: 405-408, 2000. 